\title{
An evaluation model on enterprise E-Learning system
}

\author{
Wu Bing, Song Tao
}

\author{
School of Economics and Management, Tongji University
}

\begin{abstract}
Keywords: E-Learning system, organization culture, personalization, evaluation model
Abstract. As E-Learning is widely used as a training method in enterprises, it is obviously essential to evaluate effectiveness of the E-Learning system. Although the current research mainly focus on the quality which is related with the system, two dimensions of personalization and organization culture are neglected, which play critical roles in E-Learning system. Based on the literature review, this paper proposes an evaluation model including personalization and organization culture. And a case study is used to test the effectiveness of the proposed model. The results demonstrate that the support for cultivating specific organization culture has a significant impact on the quality of E-Learning system. Finally, we make conclusions of the paper and provide the future research directions.
\end{abstract}

\section{Introduction}

Internet has become a repository of contents of all well-known formats and standards. As a result, the learning methods have changed broadly to E-Learning. And E-Learning has become an important trend for that it makes people learn without limitations of time and space.

In general, E-Learning has three characteristics: (1) effective, it can make learners interact with learning materials for maximum retention of obtained knowledge and collaborate with tutors and other learners; (2) individual, each learner can select learning materials by his/her own, (3) timely, learners can learn at any time he/she wants.

At the same time, corporations are seeking quickly and low cost training methods to meet global competitions and gain competitive advantages. Concerning the advantages of E-Learning, many enterprises have accepted E-Learning system as their new training methods.

There are many researches relating with the topic of E-Learning system evaluation. A model was proposed to illustrate the importance of E-Learning system to supply personalization for users to improve learners' satisfactory[1]. And E-Learning system should meet the E-Learning standard criteria [2]. However, the previous researches neglect the impact of organization culture when evaluating quality of E-Learning system. Consequently, in this paper in addition to personalization, organizational culture is involved in the model.

This paper is organized as follows. We survey the relating literature before the research model is proposed. Then a case study is used to illustrate the application of the proposed model. In the end, we make a conclusion and provide the future research direction.

\section{Literature Review}

Information Success model. The information system success model (ISSM) holds that system quality and information quality both depict the influence on system use and user satisfaction, while system use and user satisfaction have impacts on individuals and organization impact. The individual impact has effects on organization impact. This model provides a basic framework for other researchers and is widely adopted. After ten years, the model was updated by integrating impacts on individual and organization into net benefits and adding service quality as an evaluation indicator, intention to use to indicate users' use attitude. All the model mentioned above do not take personalization and organizational culture into account while evaluating quality of E-Learning system while this two factors are key factor influencing quality of E-Learning system.

Personalization In E-Learning System. Generally, users in an E-Learning system have different learning pace, preferences, learning needs and cognitive abilities. So E-Learning system should be able to diagnose users' learning features and according to the results recommends different courses. 
Personalization can be achieved by the student model component embedded in the E-Learning system. Student model is defined as the process before users begin learning, which gathers relevant information and represents information to be accessible and useful for particular courses. Based on current research, there are many approaches such as overlay and stereotype, machine learning, fuzzy logic theory being used to building the student model.

Organization Culture. According to Edgar Schein, organization culture refers the pattern of basic assumptions that a given group have invested, discovered or developed in learning to deal with problems ${ }^{[3]}$.

There still exist many other definitions. Based on Martin's three perspective approach ${ }^{[4]}$, we can synthesize different competing conceptualizations of organizational culture. The three perspectives are integration, differentiation and fragmentation. The integration view organizational culture as well integrated and there is consensus among members. The differentiation recognizes culture is not shared equally. Lastly, the fragmentation perspective moves beyond the clear consistencies of an integration view and clear inconsistencies of a different view. Alternatively, fragmentation studies are more likely to view ambiguity as a normal, salient, and inescapable part of organizational functioning in the contemporary world.

\section{Proposed Model and Analysis}

Based on the literature review, this paper proposes the following model, as shown in Figure 1. It is composed of information quality, system quality, service quality, personalization and support for organizational culture.

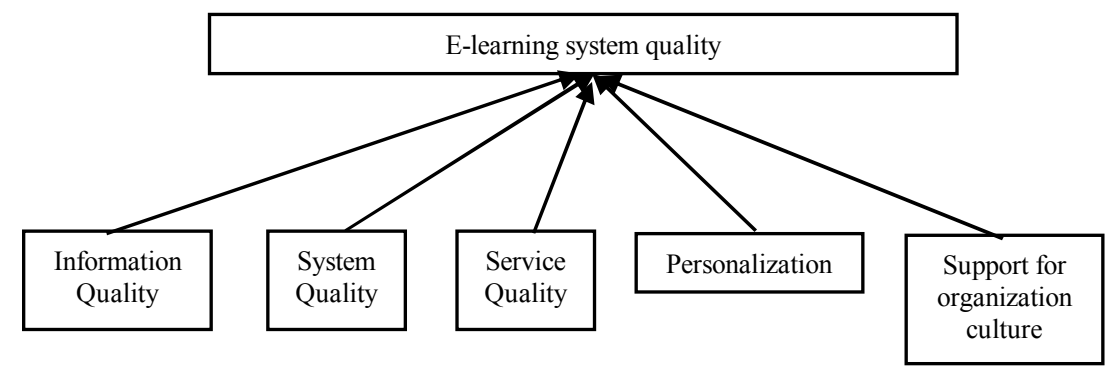

Figure 1. Evaluation model of E-Learning system quality

Information Quality. According to the quality framework of information system ${ }^{[5]}$, this paper evaluates information quality from three aspects as the followings.

Information quality includes following aspects. (1) Simplicity and amount of information, diversity of information, simplicity of content, content uniformity, content relevance and easy to understand. (2) Information nature, objective, accuracy and credibility. (3) Information timely, information efficiency and interaction time interval.

System Quality. Based on the current research and SERVQUAL framework ${ }^{[6]}$, this paper considers the following three indicators. (1) Resource of learning. Resources of learning includes all relative resources in system such as technological basis. And this can be divided into training staff, learning materials and infrastructure for learning. (2) Learning process. Learning process mainly includes two types. The first is produced from the learning experience when users actually use the system; the second is a supportive process but separated from the learning process. Learning process can be subdivided into recruitment, design of learning contents, framework and delivery of learning. (3) Learning environment. Learning environment is the background of E-Learning. It can be subdivided into online community environment and policy environment.

We set the weight of above three indicators as $0.4,0.3$ and 0.3 respectively, since resources of learning is more important than learning process and learning environment. And generally, the learning process has the same importance as learning environment.

Service Quality. Service quality can be evaluated from two aspects, namely the demand from technology and the demand from users. This paper focuses on the demand of users because of the characteristics of E-Learning. The details of indicators are listed in Table 1. 
Table 1. Evaluation indicators of service quality

\begin{tabular}{|c|c|c|}
\hline Learning materials & System & Online Community \\
\hline Timely & Ease to use & Ease of communication \\
\hline Efficiency & Stability of internet & Ease of sharing \\
\hline Diversity & System quality & Ease of learning \\
\hline Practicability & Visible interface & \\
\hline
\end{tabular}

We set the weight of three indicators as $0.3,0.3$ and 0.4 , since the ease of learning is more important than ease of communication and ease of sharing. And generally, ease of communication and ease of sharing have the same importance.

Personalization. Different learners have different learning characteristics such as learning pace, cognitive ability and so on. These differences can influence learning process and learners' satisfactory, so it is important for the E-Learning system to provide different instructional design for different users, namely personalization. This paper concerns the following two indicators .

Customized learning instruction. Before E-Learning starts, the E-Learning system gathers learners' relevant information to get learners' current state and then recommends appropriate courses to the learners.

Customized assessment. Customized assessment refers to provide learning schedules and tests for learners at specific time. The test results signify the performance of the E-Learning.

We set the weight of above two indicators as 0.5 , since the same importance of them.

Organization Culture. According to the literature review on organizational culture, the organization culture has positive effects on information adoption ${ }^{[7-8]}$. In this paper, we exam whether the E-Learning system has good support for integration of organizational culture.

\section{Case Study}

In this part, we apply the proposed model to evaluate quality of e-leaning system in $\mathrm{X}$ Airline Company in China. We sent a questionnaire to an expert group consisting of five experts in Company $\mathrm{X}$. For each item in the questionnaire, the range of score varies from 0 to 5 , in which 0 represents totally not agree and 5 represents totally agree. The weight values for the first level indicators are 0.2 . Introduction of the E-Learning Platform. Due to the large number of employees and that employees scattered all over the country in the company $\mathrm{X}$, training investments are very high, moreover it is difficult to organize effective training. Consequently, an E-Learning system was introduced in 2004 and updated it in 2008. Up to September 2013, more than 90\% employees have accepted training via E-Learning.

Evaluation of Information Quality. Table 2 shows the results received from experts. It shows the average of the overall-score is 3.3, which means information quality seems to be qualified. However, the information timely has the lowest value of 2.6. Consequently, the managers in the company $\mathrm{X}$ should pay attention to this indicator in order to improve the information quality.

Table 2 Value of information quality

\begin{tabular}{|c|c|c|c|c|}
\hline Value & Information contents & Information nature & Information timely & Overall-score \\
\hline Weight & $30 \%$ & $30 \%$ & $40 \%$ & 1 \\
\hline Expert1 & 4 & 4 & 3 & 3.6 \\
\hline Expert2 & 5 & 3 & 3 & 3.6 \\
\hline Expert3 & 4 & 4 & 2 & 3.2 \\
\hline Expert4 & 3 & 4 & 3 & 3.3 \\
\hline Expert5 & 4 & 3 & 2 & 2.9 \\
\hline Average & 4 & 3.6 & 2.6 & 3.3 \\
\hline
\end{tabular}

Evaluation of System Quality. The overall system quality of the E-Learning system is 3.3. However the score of learning process is only 2.8 .

Evaluation of Service Quality. We evaluate the service quality from the point view of users. The results show that service quality is of the same level as information quality, but is of lower quality than the system quality. 
Personalization of the E-Learning System. According to the results received from experts, the total score of personalization of the E-Learning system is 1.7, since the E-Learning system in Company X mainly provides general training courses online.

Support for Organizaiton Culture. The course in the E-Learning system are made by senior manager, and one of the goals of the E-Learning system is to provide a channel for employees to experience the organization culture, mission, vision and policy. All of the five expertise give this item 4 scores. It means that the E-Learning system can help cultivate specific organization culture in Company X.

Overall Evaluation. The overall score for E-Learning system quality is 3.24, which is not very good. In summary, the system provides basic function for E-Learning, but it doesn't contain key features of communication namely knowledge sharing and two-way communication. Meanwhile, the system has its own feature for cultivating specific organization culture.

\section{Conclusion And Future Research Directions}

In this study, we can find that information quality, system quality, service quality are have positive impact on E-Learning system quality, which is in line with previous study. Moreover support for organization culture is another critical factor influencing the quality of E-Learning system.

We integrate personalization and organization culture into the evaluation model. However the model is only applied to evaluate E-Learning system in the Company $\mathrm{X}$ in one period. Comparisons of the evaluation in different time should be made in the future research. In addition, given that the Company $\mathrm{X}$ is an airline company, the further research should focus on other companies.

\section{References}

[1] DeLone,W.H., \& McLean, E.R..The DeLone and McLean model of information systems success: a ten-year update. Journal of Management Information Systems, 19(4):9-30 (2003)

[2] Konstantina ChrysafiadiVirvouMaria. PeRSIVA: An empirical evaluation method of a student model of an intellegent E-Learning environment for computer programming, J. Computers \& Education. Vol. 68,p. 322-333 (2013)

[3] Ching-Huse ChengChen, Liang-Ying Wei, Jr-Shian ChenTai-Liang. A new E-Learning achievement evaluation model based on RBF-NN and similarity filter, J. Neural Comput \& Applic. Vol. 20, p. 659-669 (2011)

[4] Aboelmaged, Mohamed Gamal. Linking operations performance to knowledge management capability: the mediating role of innovation performance. Production planning \& Control, 25(1), p. 44-58 (2014)

[5] DeLone W, McLean E. The Delone and Mclean model of information systems success: a ten-year update. Journal of Management Information Systems 19(4): 9-30 (2003).

[6] Liu, Ying Chieh; Huang, Yu-An; Lin, Chad. Organizational Factors' Effects on the Success of E-Learning Systems and Organizational Benefits: An Empirical Study in Taiwan. International Review of Research in Open and Distance learning, 13(4), p. 130-151 (2012)

[7] Cristea, Alexandra I.; Ghali, Fawaz. Towards adaptation in E-Learning 2.0. NEW REVIEW OF HYPERMEDIA AND MULTIMEDIA, 17(2), p.199-238 (2011)

[8] Huang, Yueh-Min; Yang, Stephen J. H.; Tsai, Chin-Chung. Web 2.0 for interactive E-Learning. INTERACTIVE LEARNING ENVIRONMENTS, 17(4), p. 257-25 (2009) 